\title{
Estudo e avaliação de agregados reciclados de resíduo de construção e demolição para argamassas de assentamento e de revestimento
}

\section{(Study and evaluation of construction and demolition waste recycled aggregates for masonry and rendering mortars)}

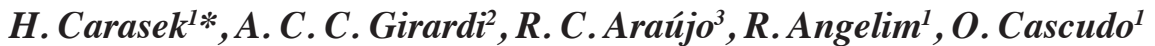 \\ ${ }^{1}$ Universidade Federal de Goiás, Escola de Engenharia Civil e Ambiental, Programa de Pós-Graduação em \\ Geotecnia, Estruturas e Construção Civil, Goiânia, GO, Brasil \\ ${ }^{2}$ Instituto Federal de Educação, Ciência e Tecnologia Goiano, Brasil \\ ${ }^{3}$ Instituto Federal de Goiás, Brasil
}

\begin{abstract}
Resumo
Este trabalho teve como objetivo realizar uma ampla caracterização de agregados reciclados (ARs) de resíduo de construção e demolição (RCD), inclusive com técnicas não convencionais, comparando-os com areia natural quartzosa. Visou também avaliar as principais características dos agregados que devem ser determinadas com vistas à dosagem de argamassas. Foram estudados três tipos de agregados: natural de rio, reciclado misto e reciclado cimentício, em granulometrias distintas. Esses agregados foram avaliados quanto à composição granulométrica (incluindo a laser), teor de material pulverulento (TMP), análise morfoscópica, absorção de água, massa unitária, massa específica e inchamento. Também foram produzidas argamassas, que foram caracterizadas quanto ao índice de consistência, densidade de massa, retração e resistências à tração na flexão e à compressão. Os resultados demonstraram que apesar da composição distinta dos RCDs, quando se utiliza o mesmo processo de britagem se obtém distribuições granulométricas muito semelhantes; no entanto, outras características são diferentes nesses agregados e essas influenciam no comportamento das argamassas e dependem da origem do resíduo. Concluiu-se que a realização de ensaios não convencionais, como granulometria a laser e morfoscopia, pode ser importante para um completo entendimento do comportamento dos ARs nas propriedades das argamassas. Ademais, a massa unitária e o TMP mostraram-se parâmetros significativos para qualificar os ARs. Palavras-chave: revestimento, assentamento, argamassa, agregado reciclado, $\mathrm{RCD}$, finos, massa unitária.
\end{abstract}

\begin{abstract}
This paper aimed to perform a wide characterization of recycled aggregates (RA), including non-conventional techniques, comparing them with natural quartz sand. It had also as objective to evaluate the main characteristics of construction and demolition waste $(C D W)$ aggregates that must be determined aiming at the mix design of mortars. For this purpose, three types of aggregates were used: river sand, mixed recycled and cementitious recycled, in two size distributions. These aggregates were evaluated concerning particles size distribution (including laser), fines content, morphoscopic analysis, water absorption, apparent dry density, specific gravity and bulking. In addition, mortars were produced and characterized by consistency, mass density, shrinkage and flexural tensile and compressive strengths. The main results showed that, despite the distinct composition of the CDW studied, when using the same crushing process, very similar grain size distributions are obtained for the RA; however, other characteristics are different in these aggregates and these influence the mortar behavior and depend on the origin of the residue. It is concluded that non-conventional tests of RA, such as laser and morphoscopic analysis, may be important for a complete understanding of their behavior in the mortar properties. In addition, apparent dry density and fines content showed significant parameters to qualify RA. Keywords: rendering, masonry, mortar, recycled aggregate, CDW, fines, apparent dry density.
\end{abstract}

\section{INTRODUÇÃO}

A construção civil é uma das atividades que mais necessita de matérias-primas naturais. No Brasil, estima-se que de $20 \%$ a $50 \%$ do total de recursos minerais explorados sejam destinados a esse setor [1]. A indústria da construção também é responsável pela maior parcela de resíduos sólidos urbanos gerados, representando, segundo a ABRELPE [2],

*hcarasek@gmail.com
$62 \%$ do total. A grande quantidade de resíduos de construção e demolição (RCD) provoca, além de impactos ambientais, prejuízos para quem o produz e para o setor público, que arca com os custos de transporte e disposição final dos resíduos, os quais muitas vezes são descartados em aterros e locais de bota-fora irregulares e sem condições de controle do meio ambiente [3-5]. Diante desse cenário, que é uma preocupação mundial, o tema de reaproveitamento de resíduos qualificados como Classe A, de acordo com a Resolução $n^{\circ} 307$ do CONAMA [6], na composição de agregados para utilização 
dentro da própria construção civil se tornou comum nas últimas décadas.

Existem diversos estudos com utilização de RCD como agregado miúdo na composição de argamassas [7-27], os quais colaboram com a formação de um banco de dados e experiência no tema. Os autores concordam na classificação dos agregados reciclados de acordo com sua composição (cimentício, cerâmico ou misto) e quanto a sua origem (construção, demolição ou restos de fábricas - olarias, concreteiras, etc.), utilizando predominantemente para isso a análise visual. Além dessa classificação de origem e composição, é frequente nas pesquisas a preocupação com a determinação do teor de material pulverulento do RCD $[4,8$, $10,14,20,21]$, visto que, em todos os casos, os agregados reciclados possuem quantidade de material pulverulento muito superior aos agregados naturais. A grande maioria dos trabalhos de argamassas com agregados reciclados tem o foco em substituições parciais do agregado natural (areia quartzosa) pelo agregado de RCD e análise da influência dos seus teores. Não são muitas as pesquisas que trabalham com substituição total dos agregados naturais pelos reciclados. Também não existem muitas pesquisas que fazem ampla caracterização dos agregados reciclados, relacionando estas características com as propriedades das argamassas.

Nesse sentido, o presente trabalho teve como objetivo realizar uma ampla caracterização dos agregados de RCD, inclusive com técnicas não muito convencionais, comparando os agregados reciclados de natureza cimentícia com os mistos (cerâmico e cimentício) e com a areia natural quartzosa, em granulometrias distintas. Visou também contribuir avaliando quais são as principais características dos agregados de RCD que devem ser determinadas com vistas à dosagem de argamassas de revestimento e assentamento de alvenarias, uma vez que na pesquisa são testadas correlações dos parâmetros dos agregados com o comportamento das argamassas no estado fresco e endurecido.

\section{EXPERIMENTAL}

Materiais utilizados: para a realização do programa experimental, foram selecionados dois tipos de agregados reciclados compostos por resíduo de construção: o primeiro, misto de material cerâmico $(50 \%)$ e cimentício (50\%), denominado neste trabalho AMis; o segundo, predominantemente cimentício, designado ACim. Além destes, foi utilizada uma areia natural lavada de leito de rio, denominada de ANat. Os agregados AMis e ANat foram estudados em duas granulometrias, a saber: material passante na peneira com abertura $3,15 \mathrm{~mm}$ (da série intermediária) e com abertura de $1,18 \mathrm{~mm}$ (da série normal). $\mathrm{O}$ agregado $\mathrm{ACim}$ foi avaliado apenas na granulometria passante na abertura de $3,15 \mathrm{~mm}$. Na Tabela I são apresentados os agregados utilizados na pesquisa com as respectivas nomenclaturas adotadas. Os agregados foram amplamente caracterizados, sendo que os métodos adotados para este fim e os resultados estão explicitados nas próximas seções. Na produção das argamassas, empregou-se um cimento Portland CP II Z-32 RS (Tabela II) e uma cal hidratada CH-I (Tabela III). Observa-se que ambos os materiais atenderam em todos os parâmetros às exigências das normas brasileiras.

Tabela I - Variáveis estudadas - agregados utilizados. [Table I - Variables studied - aggregates used.]

\begin{tabular}{ccc}
\hline Material & $\begin{array}{c}\text { Abertura da } \\
\text { peneira }(\mathrm{mm})\end{array}$ & Denominação \\
\hline Areia natural & 3,15 & ANat3 \\
& 1,18 & ANat1 \\
$\begin{array}{c}\text { Agregado reciclado misto } \\
\text { (cerâmico e cimentício) } \\
\begin{array}{c}\text { Agregado reciclado } \\
\text { cimentício }\end{array}\end{array}$ & 3,15 & AMis3 \\
\hline
\end{tabular}

Tabela II - Características físicas e químicas do cimento Portland CP II Z - 32 RS. [Table II - Physical and chemical characteristics of Portland cement CP II Z - 32 RS.]

\begin{tabular}{cccc}
\hline Método de ensaio & Propriedade & Resultado & $\begin{array}{c}\text { Parâmetro normativo } \\
\text { da NBR 11578:1991 }\end{array}$ \\
\hline NBR NM 23:2001 & Massa específica $\left(\mathrm{kg} / \mathrm{dm}^{3}\right)$ & 2,98 & ND \\
NBR NM 76:1998 & Finura Blaine $\left(\mathrm{m}^{2} / \mathrm{kg}\right)$ & 354 & $\geq 260$ \\
NBR 11579:1991 & Resíduo na peneira 0,075 mm (\%) & 2,1 & $\leq 12$ \\
NBR 12826:1993 & Resíduo na peneira 0,045 mm (\%) & 10,6 & Não especificado \\
& Tempo de início de pega (h) & 3,5 & $\geq 1$ \\
NBR NM 65:2003 & Tempo de fim de pega (h) & 4,25 & $\leq 10$ \\
& Resistência à compressão 3 dias (MPa) & 27,6 & $\geq 10,0$ \\
NBR 7215:1996 & Resistência à compressão 7 dias (MPa) & 33,8 & $\geq 32,0$ \\
& Resistência à compressão 28 dias (MPa) & 41,9 & $\leq 6,5$ \\
NBR NM 14:2012 & Teor de MgO (\%) & 3,24 & $\leq 4,0$ \\
\hline
\end{tabular}


Tabela III - Caracterização física e química da cal hidratada CH-I.

[Table III - Physical and chemical characteristics of lime CH-I.]

\begin{tabular}{cccc}
\hline Método de ensaio & Propriedade & Resultado & $\begin{array}{c}\text { Parâmetro normativo } \\
\text { da NBR 7175:2003 }\end{array}$ \\
\hline \multirow{2}{*}{ NBR 6473:2003 } & Anidrido carbônico, $\mathrm{CO}_{2}(\%)$ & 4,05 & $\leq 5,0$ \\
& Óxidos de Ca e Mg não hidratados $(\%)$ & 5,96 & $\leq 10,0$ \\
& Óxidos totais na base de não voláteis $(\%)$ & 97,04 & $\geq 90,0$ \\
NBR 9289:2000 & Finura peneira 0,6 mm (\%) & 0,30 & $\leq 5,0$ \\
& Finura peneira 0,075 mm (\%) & 9,10 & $\leq 10,0$ \\
NBR 9206:2003 & Plasticidade $(\%)$ & 120,8 & $\geq 110,0$ \\
NBR NM 23:2001 & Massa unitária $\left(\mathrm{kg} / \mathrm{dm}^{3}\right)$ & 0,45 & Não especificado \\
NBR NM 23:2001 & Massa específica $\left(\mathrm{kg} / \mathrm{dm}^{3}\right)$ & 2,45 & Não especificado \\
\hline
\end{tabular}

Caracterização dos agregados: o agregado reciclado misto foi obtido na Usina RNV Resíduos e o agregado reciclado cimentício na Usina ECODOL Revitalize, ambas localizadas na cidade de Aparecida de Goiânia, região metropolitana de Goiânia - GO. Apesar de serem duas usinas distintas, o processo de obtenção dos agregados foi similar, ou seja, ambos foram produzidos por meio de moagem dos resíduos de construção em britador de mandíbulas (britagem primária) e, posteriormente, em britador de impacto (secundária). O agregado reciclado cimentício (ACim) teve sua origem em resíduos de usinas concreteiras da região, sendo constituído por sobras de concreto nos caminhões betoneira e de produtos de sua lavagem. Tendo em vista nesta pesquisa o emprego de resíduos de usinas comerciais, não se teve a informação da idade desses resíduos de origem cimentícia. Sabe-se que a idade, neste caso, influi no grau de hidratação do cimento Portland. Resíduos com idades mais avançadas são praticamente inertes, enquanto que os de materiais provenientes de misturas recentes de cimento com água ainda podem apresentar certa capacidade cimentante. Este aspecto pode influenciar as características e propriedades das argamassas e concretos elaborados com RCD cimentício. No entanto, como os RCDs empregados nesta pesquisa são produzidos em usinas comerciais, esta variável não foi controlada. No caso do agregado misto (AMis), a parcela cimentícia provém de resíduos de blocos de concreto quebrados, além de restos de concreto e argamassa de canteiros de obras, enquanto que a parte cerâmica foi oriunda de blocos e telhas que foram danificados no transporte ou durante a execução dos serviços nas obras. Autores $[4,10]$

Tabela IV- Métodos para análise das características dos agregados.

[Table IV - Methods for analysing the characteristics of aggregates.]

\begin{tabular}{|c|c|c|}
\hline Característica & Finalidade & Método \\
\hline $\begin{array}{l}\text { Composição } \\
\text { granulométrica }\end{array}$ & $\begin{array}{l}\text { Mostrar a distribuição das dimensões das partículas } \\
\text { constituintes dos agregados, com determinação do módulo } \\
\text { de finura e dimensões máximas características }\end{array}$ & $\begin{array}{l}\text { NBR 7211:2009; } \\
\text { NBR NM 248:2003 }\end{array}$ \\
\hline Granulometria a laser & Verificar a distribuição granulométrica das partículas inferiores a $2 \mathrm{~mm}$ & {$[28]$} \\
\hline $\begin{array}{l}\text { Teor de material } \\
\text { pulverulento }\end{array}$ & Determinar a quantidade de material com granulometria inferior a $75 \mu \mathrm{m}$ & NBR NM 46:2003 \\
\hline Absorção de água & $\begin{array}{l}\text { Determinar o acréscimo de massa dos grãos porosos em relação à massa } \\
\text { no estado seco, devido à penetração de água nos poros permeáveis }\end{array}$ & NBR NM 30:2001 \\
\hline Massa unitária & $\begin{array}{c}\text { Determinar a massa que as partículas do agregado ocupam } \\
\text { em determinado volume (densidade aparente) }\end{array}$ & NBR NM 45:2006 \\
\hline Massa específica & $\begin{array}{l}\text { Estabelecer a relação entre a massa do agregado na condição saturada } \\
\text { superfície seca e seu volume, excluindo os poros permeáveis (densidade real) }\end{array}$ & NBR NM 52:2009 \\
\hline $\begin{array}{l}\text { Interação (encaixe } \\
\text { espontâneo) entre as } \\
\text { partículas }\end{array}$ & $\begin{array}{l}\text { Associar as massas unitária e específica dos grãos para se obter } \\
\text { o fator de empacotamento, o índice de vazios e a porosidade dos agregados }\end{array}$ & [29] \\
\hline $\begin{array}{l}\text { Análise por imagem } \\
\text { (análise morfoscópica) }\end{array}$ & $\begin{array}{l}\text { Determinar o índice de forma dos grãos a partir de relações } \\
\text { entre os diâmetros, perímetro e área dos agregados }\end{array}$ & {$[30]$} \\
\hline $\begin{array}{l}\text { Coeficiente de inchamento } \\
\text { e umidade crítica }\end{array}$ & $\begin{array}{l}\text { Determinar a variação do volume aparente dos grãos com a variação de } \\
\text { umidade e a umidade a partir do qual o coeficiente de inchamento é constante }\end{array}$ & NBR 6467:2006 \\
\hline
\end{tabular}


sugerem que, após a produção do agregado com RCD, seja feita a retirada do material pulverulento por meio de lavagem ou separabilidade por líquidos densos. Entretanto, a fim de assegurar a sustentabilidade do reaproveitamento de resíduos sem gerar sub-resíduos e gastar água (recurso natural não renovável), optou-se por trabalhar com os agregados reciclados sem a retirada da fração fina. A areia natural, de quartzo e lavada, foi procedente do rio Caiapó, Goiás. Para realizar uma caracterização completa das amostras das areias naturais e recicladas, foram utilizados tanto procedimentos adotados para a avaliação de agregados para a construção civil quanto para solos. Na Tabela IV está apresentado um resumo das avaliações realizadas. A metodologia empregada para realização dos procedimentos que não possuem normalização específica para agregados da construção civil é apresentada na sequência.

Granulometria a laser: o caráter desta pesquisa requer uma análise detalhada das partículas, principalmente da fração fina; isto é fundamental quando se trabalha com materiais britados, em que o volume de finos é importante. Neste caso, o método convencional de peneiramento é limitado por não ser possível realizá-lo em aberturas inferiores a $0,075 \mathrm{~mm}$, uma vez que o movimento vibratório da peneira eletriza as partículas fazendo com que elas fiquem retidas e aderidas na malha metálica por atração eletrostática. Dessa forma, procedeu-se a análise com granulômetro a laser (Microtrac, S3500), desde o limite superior do aparelho, de $2 \mathrm{~mm}$, até o limite inferior, de $243 \mu \mathrm{m}$. Por não haver norma brasileira que regulamenta o ensaio, foi utilizada metodologia proposta em [28], para solos tropicais. Para tanto, os agregados foram previamente passados na peneira de abertura de $2 \mathrm{~mm}$. Inicialmente as amostras não sofreram nenhum pré-tratamento. Para os agregados reciclados foi realizada também uma análise após a aplicação de ultrassom nas amostras, com potência de 30 $\mathrm{W}$ durante $60 \mathrm{~s}$. Este pré-tratamento teve intuito de desfazer possíveis agregações no material. Adotou-se um índice de refração de 1,54 para a areia natural, valor representativo do quartzo, considerado o composto mais presente na composição mineralógica desse material. Já para os agregados reciclados, o índice de refração adotado foi de 1,81 , valor este que neutralizou o índice de refração do material no algoritmo do equipamento, uma vez que a composição do RCD é bem variada.
Análise morfoscópica: os grãos foram avaliados por meio de morfoscopia, realizada em lupa estereoscópica (Leica Mycrosystems, MZ12.5), com uma câmera acoplada ao computador. Foram avaliados dez grãos de cada uma das frações retidas nas peneiras da série normal, além do material retido e passante (fundo) na peneira com abertura $0,075 \mathrm{~mm}$. Isto resultou em um total de 350 grãos medidos e analisados. Os agregados das frações 2,4-1,2, 1,2-0,6 e 0,6$0,3 \mathrm{~mm}$ foram ampliados 18 vezes; para os grãos de $0,3-0,15$ mm a ampliação foi de 30 vezes e as partículas de dimensão inferior a $0,15 \mathrm{~mm}$ foram ampliadas em 60 vezes. A análise das imagens foi realizada por meio do software AutoCAD ${ }^{\circledR}$, em que foram realizadas medidas dos diâmetros da maior circunferência inscrita no grão (D2) e da menor circunferência que circunscreve o grão (D1), além da área projetada do grão e seu perímetro. Na Fig. 1 estão exemplificados os traçados utilizados para a obtenção dos valores da análise. Para o cálculo do índice de forma (Eq. A), da esfericidade (Eq. B) e dof-circle (Eq. C) dos grãos, foram adotadas as equações:

$$
\begin{aligned}
\mathrm{IF} & =\frac{\mathrm{D}_{2}}{\mathrm{D}_{1}} \\
\phi & =\left(\frac{4 \mathrm{Ap}}{\pi}\right)^{\frac{1}{2}} \times \frac{1}{\mathrm{D}_{1}} \\
\mathrm{fc} & =\frac{4 \pi \mathrm{Ap}}{\mathrm{p}^{2}}
\end{aligned}
$$

em que: IF - índice de forma, adimensional; $\mathrm{D}_{1}$ - diâmetro da menor circunferência que circunscreve o grão, em mm; $\mathrm{D}_{2}$ diâmetro da maior circunferência inscrita no grão, em mm; $\phi$ - esfericidade do grão, mm/mm; Ap - área projetada do grão, em $\mathrm{mm}^{2}$; fc - circunferência do grão (f-circle), em mm²/ $\mathrm{mm}^{2}$; $\mathrm{P}$ - perímetro do grão, em mm.

Preparo e caracterização das argamassas: a fimde verificar a influência dos agregados nas características e propriedades das argamassas, foram elaboradas misturas de composição e consistência típicas de assentamento e de revestimento de alvenarias. O traço definido para as argamassas com agregado reciclado foi 1:5,8 (cimento e agregado reciclado, em massa). Para as argamassas com areia natural, o traço adotado foi 1:1:5,8 (cimento, cal e agregado natural, em
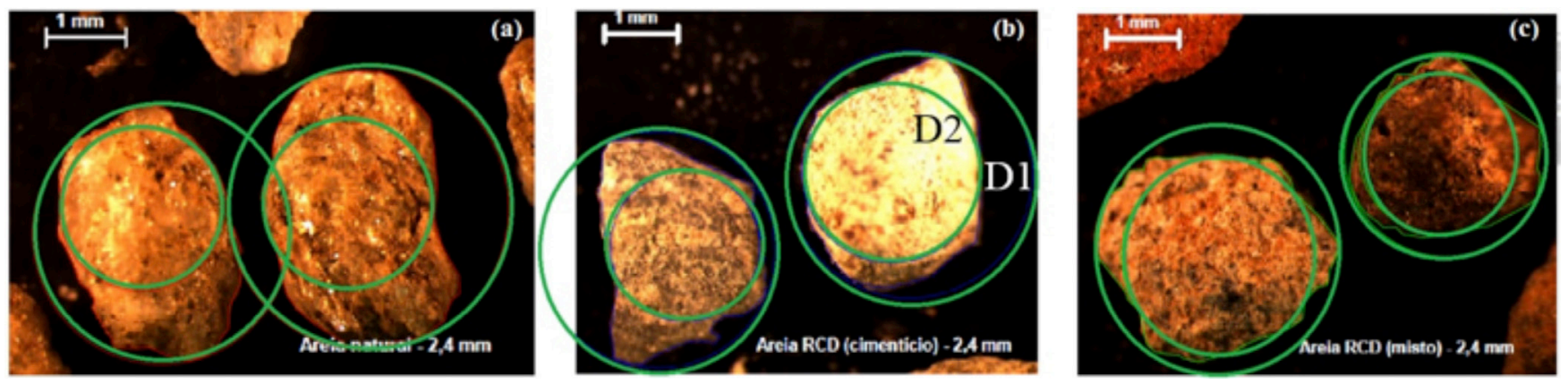

Figura 1: Medições realizadas na análise por imagem dos agregados: (a) ANat; (b) ACim; e (c) AMis.

[Figure 1: Measurements performed in the image analysis of aggregates: (a) ANat; (b) ACim; and (c) AMis.] 
massa). Os traços têm em comum, além da mesma proporção de agregados em relação ao cimento, o teor de finos total igual $(28 \pm 1) \%$, quando as argamassas são preparadas com os agregados passantes na peneira $3,15 \mathrm{~mm}$. O teor de finos total da argamassa, também chamado de finos total plastificante, é calculado considerando a contribuição de todos os materiais da argamassa anidra que têm partículas inferiores a $0,75 \mathrm{~mm}$, independentemente de ser aglomerante (cimento ou cal) ou inerte (agregados) [31]. Como o teor de material pulverulento da areia natural (ANat3) foi menor do que o teor dos agregados reciclados (AMis3 e ACim3), no traço de argamassa com areia natural foi adicionada cal, garantindo-se assim uma plasticidade adequada e um teor de finos total próximo ao das demais argamassas. Apenas no caso da argamassa preparada com AMis1, o teor de finos ficou inferior ao das demais argamassas; isto porque se optou por trabalhar com o traço sem cal, de forma a se poder compará-la diretamente com a argamassa elaborada com o mesmo agregado, mas passado na peneira mais grossa (AMis3). Fixou-se também a relação água/materiais secos em $(22,5 \pm 2,5) \%$, faixa esta que garantiu trabalhabilidade adequada para todas as argamassas, determinada em um estudo piloto. As argamassas foram homogeneizadas utilizando-se betoneira convencional de obra. Foi realizada inicialmente, durante aproximadamente 30 $\mathrm{s}$, a mistura dos agregados com água para que atingissem uma situação de semissaturação (conforme proposto em [17, 32]); em seguida, adicionaram-se os aglomerantes (cimento e cal) e complementou-se com água até atingir a trabalhabilidade desejada, misturando-se por mais 2 min. Foram, então, realizados os ensaios de caracterização das argamassas no estado fresco: determinação da densidade de massa (NBR 13278:2005) e determinação do índice de consistência flow table (NBR 13276:2002). Também foram moldados os corpos de prova para a verificação da retração ao longo de 28 dias (NBR 15261:2005) e determinação das resistências à compressão e à tração na flexão (NBR 13279:2005).

\section{RESULTADOS E DISCUSSÃO}

\section{Características dos agregados}

As curvas de distribuição granulométrica dos agregados podem ser observadas na Fig. 2. A título de comparação, também está apresentado o intervalo recomendado pela ASTM C-897:2015, com parâmetros para os agregados usados em argamassas de assentamento e de revestimento. Nas curvas granulométricas, percebe-se que, apesar da diferença de composição e origem dos agregados reciclados, o fato de o processo de moagem ser o mesmo gerou distribuições granulométricas contínuas e muito semelhantes entre os agregados AMis3 e ACim3. Comparando-se estes agregados com a areia natural ANat3, eles possuíram menor percentual retido acumulado de grãos menores que $0,15 \mathrm{~mm}$, o que indicou uma maior quantidade de finos destes materiais, comprovado posteriormente também no ensaio de determinação do teor de material pulverulento (Tabela V). Com relação aos limites de norma, apenas ANat1 aproximou-se do intervalo recomendado pela ASTM C-897:2015, enquanto que os demais agregados, inclusive a areia natural (ANat3), que é utilizada nesta granulometria correntemente nas obras locais, não atenderam ao requisito normativo.

A Tabela $\mathrm{V}$ resume as principais características dos agregados estudados, determinadas em ensaios, e também os parâmetros calculados com base nesses resultados. Comparando-se os agregados que foram passados na peneira 3,15 mm (ANat3, AMis3 e ACim3), conforme esperado pela avaliação das curvas granulométricas, o teor de material pulverulento (TMP) resultou muito superior nos agregados reciclados (cerca de 3 a 4 vezes o valor obtido

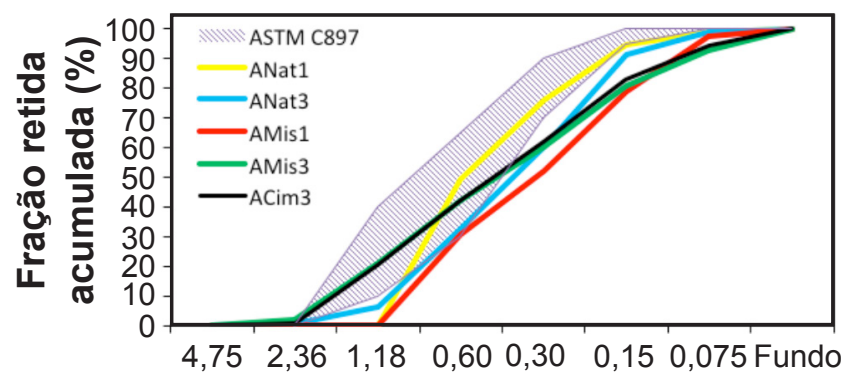

Abertura de peneira $(\mathrm{mm})$

Figura 2: Curva de distribuição granulométrica dos agregados. [Figure 2: Particle size distribution curve of the aggregates.]

Tabela V - Características determinadas para os agregados estudados.

[Table V-Characteristics determined for the studied aggregates.]

\begin{tabular}{ccccccccccccc}
\hline Agregado & $\begin{array}{c}\text { DMC } \\
(\mathrm{mm})\end{array}$ & MF & $\begin{array}{c}\text { TMP } \\
(\%)\end{array}$ & $\begin{array}{c}\text { ABS } \\
(\%)\end{array}$ & $\begin{array}{c}\text { ME } \\
\left(\mathrm{g} / \mathrm{cm}^{3}\right)\end{array}$ & $\begin{array}{c}\mathrm{MU} \\
\left(\mathrm{g} / \mathrm{cm}^{3}\right)\end{array}$ & $\mathrm{e}$ & $\begin{array}{c}\eta \\
(\%)\end{array}$ & $\begin{array}{c}\text { Eo } \\
(\%)\end{array}$ & $\phi$ & $\begin{array}{c}\mathrm{UC} \\
(\%)\end{array}$ & $\mathrm{CI}$ \\
\hline ANat1 & 1,18 & 1,91 & 1,62 & 0,85 & 2,70 & 1,43 & 0,89 & 0,47 & 0,53 & 0,78 & 6,30 & 1,40 \\
ANat3 & 2,36 & 2,20 & 4,10 & 2,97 & 2,73 & 1,44 & 0,89 & 0,47 & 0,53 & 0,79 & 8,50 & 1,49 \\
AMis1 & 1,18 & 1,62 & 6,58 & 6,11 & 2,68 & 1,21 & 1,22 & 0,55 & 0,45 & 0,79 & 21,00 & 1,53 \\
AMis3 & 2,36 & 2,07 & 13,96 & 12,01 & 2,69 & 1,46 & 0,85 & 0,46 & 0,54 & 0,79 & 16,60 & 1,66 \\
ACim3 & 2,36 & 2,09 & 17,60 & 16,58 & 2,54 & 1,28 & 0,99 & 0,50 & 0,50 & 0,81 & 19,20 & 1,50 \\
\hline
\end{tabular}

Notas: DMC - dimensão máxima característica; $M F$ - módulo de finura; TMP - teor de material pulverulento; ABS - absorção de água do agregado; ME - massa específica real dos grãos; $M U$ - massa unitária; $e$ - índice de vazios não compactado (=ME/MU -1); $\eta$ - porosidade [=e/(1+e).100]; Eo - fator de empacotamento

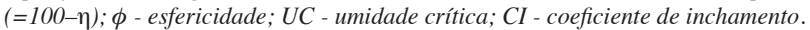


para ANat3). O maior TMP foi obtido para o agregado reciclado cimentício. A passagem dos agregados em peneira com abertura menor $(1,18 \mathrm{~mm})$ levou a uma redução do material pulverulento dos agregados para cerca de metade do teor inicial, tanto para a areia natural como para a areia de RCD misto. Isto aconteceu tendo em vista que o peneiramento realizado simulou a operação de obra, em peneira aberta, o que gerou grande dispersão das partículas finas na atmosfera. Em termos dos parâmetros normativos da NBR 15116:2004 os agregados reciclados atenderiam ao limite máximo de material pulverulento, $20 \%$, especificado para agregados reciclados de composição mista visando o preparo de concreto sem função estrutural.

Foi realizado, também, o ensaio de granulometria a laser nas amostras de agregado visando inferir-se sobre as dimensões das partículas mais finas, uma vez que esta é uma limitação do método convencional por peneiramento. A Fig. 3 apresenta os resultados obtidos para as três areias (partindo-se das amostras originais dos agregados, mais grossas, passadas na peneira de $2 \mathrm{~mm}$, limite superior de medição do equipamento), sem pré-tratamento e também após o tratamento com ultrassom. Observa-se que os agregados reciclados, além de possuírem os maiores teores de material pulverulento (TMP), apresentaram finos menores do que a areia natural, com partículas inferiores a $10 \mu \mathrm{m}$ para AMis e ACim (enquanto que para ANat o menor diâmetro foi superior a $60 \mu \mathrm{m}$ ). Comparando-se os resultados dos agregados reciclados com e sem aplicação do ultrassom, percebe-se que houve um afastamento das curvas granulométricas. A aplicação do ultrassom produziu aumento na fração de partículas finas, principalmente na fração inferior a $300 \mu \mathrm{m}$, devido à desagregação dos grãos que estavam ligados por atração eletrostática, causada pelo processo dinâmico de britagem do resíduo. Observou-se também que no agregado reciclado cimentício a fração mais fina foi constituída de partículas um pouco menores, mas com diferenças pouco significativas entre ACim e AMis.

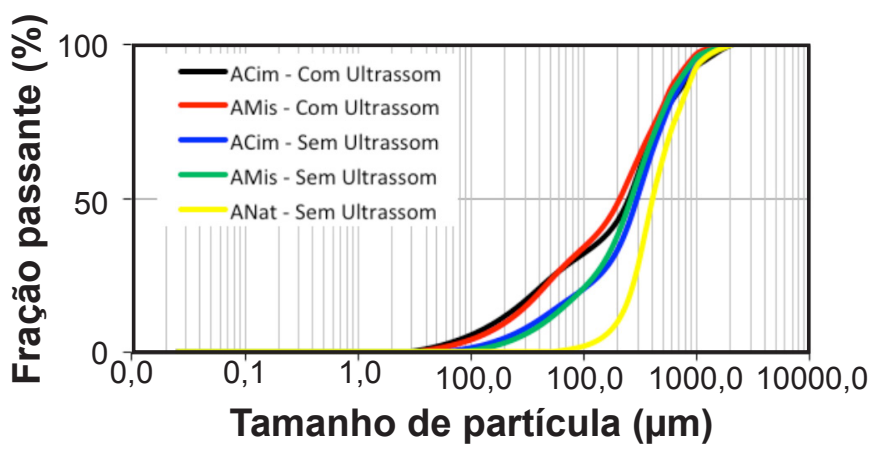

Figura 3: Curva de granulometria a laser dos agregados. [Figure 3: Particle size distribution curves by laser diffraction.]

Na Tabela V, nota-se que a absorção de água dos agregados seguiu a mesma tendência dos resultados do teor de pulverulentos, ou seja, cresceu para os agregados mais grossos e foi superior nos agregados reciclados em comparação com a areia natural. Observa-se também que o agregado reciclado de origem cimentícia foi o que apresentou a maior absorção de água dentre todos os materiais testados. Esse resultado foi contrário ao encontrado por outros autores $[10,14]$, que indicaram que o agregado reciclado cerâmico possui maior absorção quando comparado ao cimentício. Este fato pode ser explicado em função da origem do agregado cimentício empregado na presente pesquisa; o material utilizado foi proveniente de sobras de concreto de caminhão betoneira, o qual não foi vibrado ou adensado, além de ter sua relação água/cimento bastante elevada devido à adição de água na lavagem do caminhão. Isto levou a uma elevada porosidade do agregado, como pode ser visto na Fig. 4. Essa divergência corrobora a importância de se analisar a origem do resíduo para a produção do agregado reciclado e não somente a sua composição, visto que em outras pesquisas o agregado cimentício foi obtido da demolição de estruturas de concreto armado, apresentando alta densidade; nestes casos, o agregado cimentício mais denso também apresenta menores TMPs, resultado oposto ao obtido no presente trabalho. Da mesma forma que para o teor de pulverulentos, os agregados reciclados da pesquisa atenderiam ao limite máximo de absorção de água, especificado em 17\% para agregados reciclados de composição mista visando o preparo de concreto sem função estrutural (NBR 15116:2004), mas não atenderiam o limite máximo de $12 \%$, especificado para agregados de composição cimentícia.

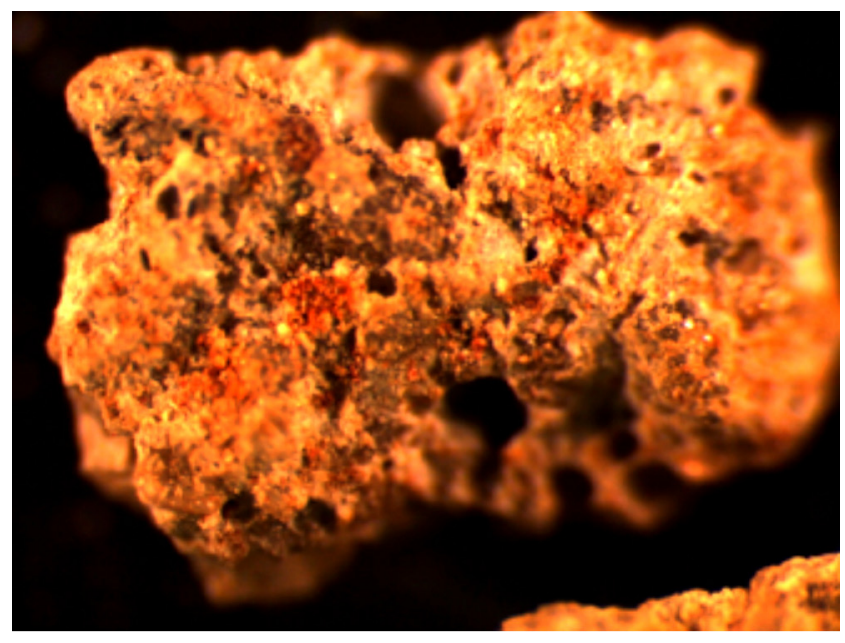

Figura 4: Grão de agregado reciclado cimentício observado na lupa estereoscópica, onde se pode notar a alta porosidade do material. [Figure 4: Grain of cementitious recycled aggregate observed in the stereo microscope; high porosity of the material can be observed.]

Na Fig. 5 é apresentada a correlação encontrada entre o teor de finos (TMP) e a absorção de água dos agregados estudados. A análise permitiu fazer duas observações. A primeira foi o incremento da absorção de água dos agregados à medida que aumentou o teor de pulverulentos, que pode ser explicado pelo aumento da superfície específica do material. $\mathrm{O}$ aumento da área específica propicia maior superfície para adsorção física das moléculas de água.É importante ressaltar que a água é constituída de moléculas polares, as quais apresentam assimetria na distribuição de cargas elétricas [33]. 
Isto favorece a adsorção de um volume maior de moléculas de água por mecanismos de atração eletrostática, seja ao redor das partículas, seja nas paredes internas dos poros dos grãos maiores (como se notou também na relação entre a umidade crítica e o TMP dos agregados mostrada abaixo). $\mathrm{O}$ valor do coeficiente de determinação $\left(\mathrm{R}^{2}\right)$ próximo de 1,0 demonstrou a força da correlação encontrada entre TMP e absorção de água dos agregados estudados. A segunda observação foi a ordem com que apareceram os materiais na curva (silicosos - ANat, cerâmicos - AMis, e cimentícios - ACim, nesta ordem crescente do teor de finos), dando condições para comentar sobre a natureza dos materiais. Os agregados de natureza silicosa possuíram menos finos, pois não passaram por britagem. Os RCDs possuíram maiores teores de finos, com destaque para os cimentícios que, por serem mais porosos e, consequentemente, mais frágeis ao processo de britagem, produziram mais finos. Quanto ao tamanho dos finos a granulometria a laser demonstrou que os agregados reciclados (mistos e cimentícios) foram semelhantes e ambos foram mais finos do que o silicoso (areia natural).

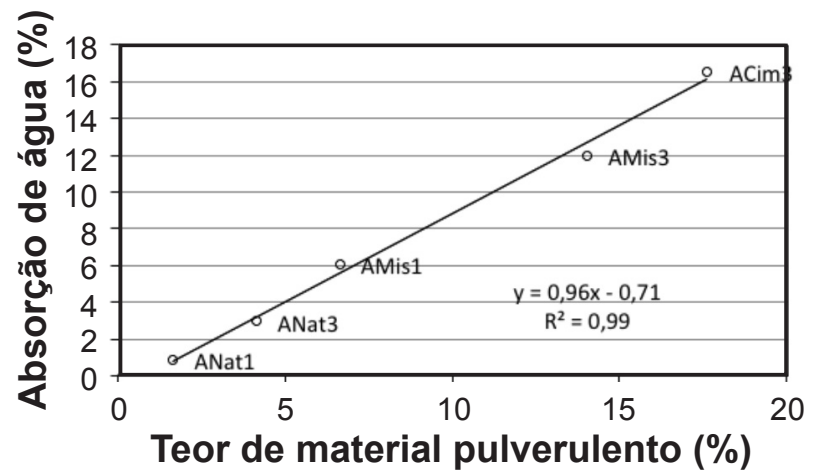

Figura 5: Relação entre a absorção de água dos agregados e o teor de material pulverulento.

[Figure 5: Relationship between the water absorption and the fine content of aggregates.]

Quanto aos resultados de massa específica (ME) dos grãos, os agregados estudados apresentaram valores próximos (entre 2,54 e 2,73 $\mathrm{g} / \mathrm{cm}^{3}$ ), resultado este similar ao obtido por outros autores $[10,20,34]$. Em contrapartida, em [14] foram obtidas diferenças de ME mais significativas entre agregados de resíduo cerâmico $\left(2,06 \mathrm{~g} / \mathrm{cm}^{3}\right)$, de resíduo de concreto $\left(2,38 \mathrm{~g} / \mathrm{cm}^{3}\right)$ e a areia natural $\left(2,59 \mathrm{~g} / \mathrm{cm}^{3}\right)$. O conjunto de resultados discutidos anteriormente (TMP, absorção e ME) permite inferir que os agregados provenientes de RCD não podem ser classificados apenas quanto à composição do material (cerâmico ou cimentício), devendo ser feita uma avaliação ampla das suas características, as quais podem ser muito variáveis de acordo com a origem do resíduo e do seu processamento. Com relação à massa unitária (MU), os agregados ACim3 e AMis1 obtiveram valores inferiores $\left(1,28\right.$ e $1,21 \mathrm{~g} / \mathrm{cm}^{3}$, respectivamente) aos dos agregados AMis $3\left(1,46 \mathrm{~g} / \mathrm{cm}^{3}\right)$, ANat3 $\left(1,43 \mathrm{~g} / \mathrm{cm}^{3}\right)$ e ANat1 $\left(1,44 \mathrm{~g} / \mathrm{cm}^{3}\right)$. As variações observadas nos valores de MU não foram tão altas $(17 \%$ entre o maior e o menor valor obtido) e podem ser explicadas pelo encaixe espontâneo de suas partículas decorrentes da sua distribuição granulométrica (quantidade e tamanho dos grãos) e da forma dos grãos (pouco significativa para os materiais testados nesta pesquisa, como discutido a seguir), além das variações da ME. Para avaliar essa interação, realizou-se a análise conjunta dessas características, no estado solto, calculando-se o índice de vazios (e), a porosidade $(\eta)$ e o fator de empacotamento (Eo) de cada agregado. Os resultados obtidos (Tabela V) demonstraram que, nos três parâmetros (que são complementares), os agregados ANat1, ANat3 e AMis3 apresentaram comportamento semelhante, enquanto o índice de vazios foi maior para ACim3 e AMis1. Ademais, visando à completa avaliação dos grãos, foram realizadas as análises das imagens na lupa estereoscópica para determinação do grau de esfericidade e forma dos grãos (Fig. 6). As médias ponderadas (em função das faixas granulométricas) para o índice de forma (IF), a esfericidade e o f-circle dos agregados, obtidas por meio da análise morfoscópica, são apresentadas na Tabela VI. Quanto ao índice de forma, os agregados foram considerados cúbicos

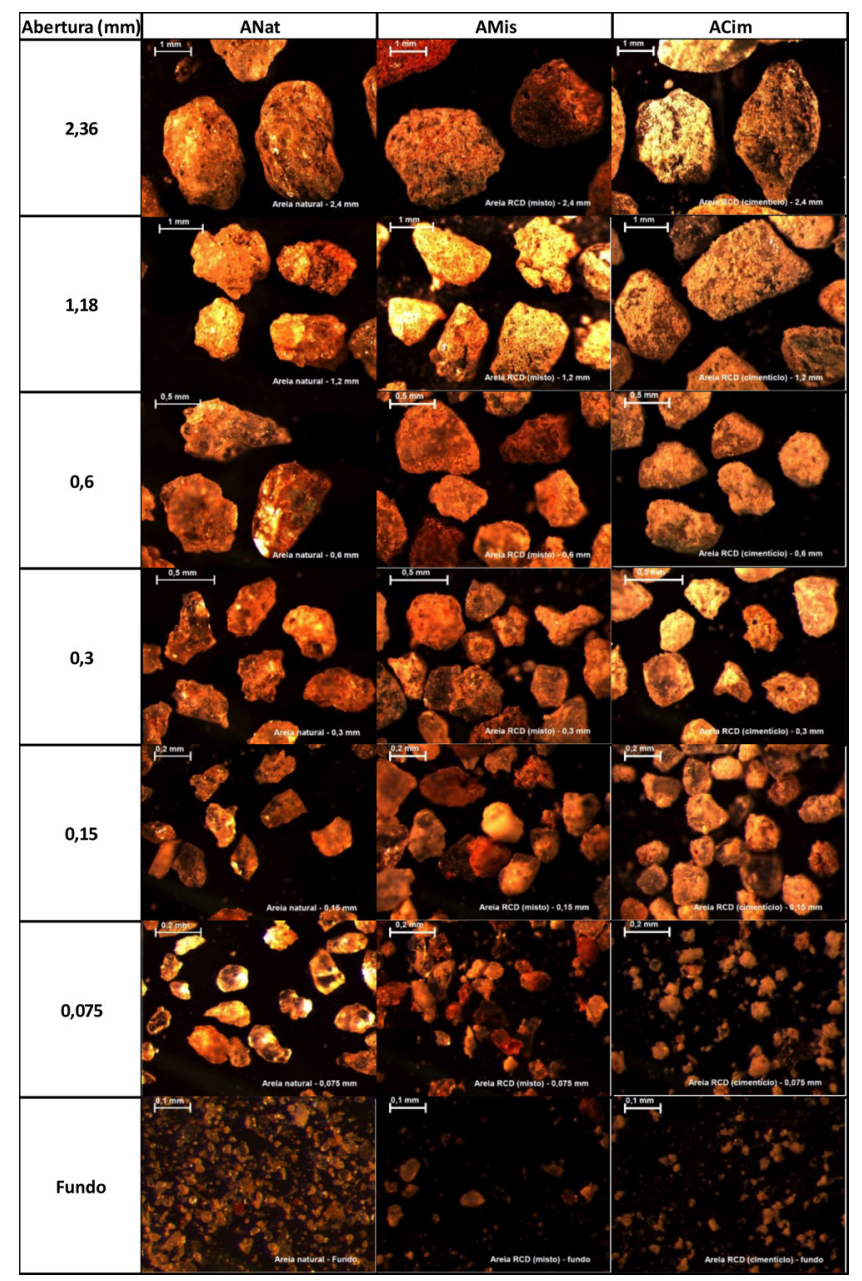

Figura 6: Imagens dos agregados obtidas por meio de lupa estereoscópica.

[Figure 6: Images of the aggregates obtained by means of a stereo microscope.] 
Tabela VI - Resultados da análise por imagem dos agregados. [Table VI - Results of the aggregates image analysis.]

\begin{tabular}{cccc}
\hline Agregado & IF & Esfericidade & $f$-circle \\
\hline ANat1 & 0,62 & 0,78 & 0,80 \\
ANat3 & 0,62 & 0,79 & 0,81 \\
AMis1 & 0,64 & 0,79 & 0,82 \\
AMis3 & 0,64 & 0,79 & 0,81 \\
ACim3 & 0,65 & 0,81 & 0,82 \\
\hline Parâmetro: $0 \leq f$-valor $<0,25:$ muito alongado; $0,25 \leq f$-valor $<0,50:$ \\
alongado; $0,50 \leq f$-valor $<0,75:$ cúbico; $0,75 \leq f$-valor $\leq 1$ : circular.
\end{tabular}

e, quanto à esfericidade e $f$-circle, foram classificados como circulares. Não houve diferenças significativas entre os agregados estudados, indicando a eficiência na produção dos agregados reciclados (forma de cominuição dos resíduos), que obtiveram equivalência de formato com o agregado natural.

Foi determinado, também, o inchamento dos agregados estudados (Fig. 7). Nas curvas de inchamento em função do teor de umidade, percebeu-se um comportamento diferenciado relacionado aos agregados reciclados. Para estes agregados, devido à sua elevada absorção de água, houve um retardo no início do inchamento, havendo inicialmente uma manutenção do volume e até mesmo uma pequena retração do material (em teores de umidade inferiores a $5 \%$ para oagregado AMis $3 \mathrm{e} 7 \%$ para os agregados AMis1 e ACim3). Apesar do inchamento ser um ensaio convencional para agregados de concretos e argamassas, é interessante destacar que na literatura não foram encontrados trabalhos que discutam resultados da curva de inchamento de agregados de RCD. Tal comportamento dos agregados reciclados é similar ao de agregados naturais contendo alto teor de finos (argilominerais), como os saibros, como pode ser confirmado em [35]. A literatura em geral, contudo, não evidencia esse comportamento e, tampouco, aprofunda-se nas discussões desse retardo do inchamento para o caso de agregados saibrosos e de RCD. Muito provavelmente, a mudança de comportamento da curva de inchamento quando se têm agregados com altos teores de finos (ocasionando o retardo inicial) se dá em função da absorção inicial de água no interior dos grãos porosos. Durante esta etapa inicial de absorção, não ocorre inchamento, que, com efeito, somente acontece mediante a adsorção de água no entorno das partículas (ação que vem em um segundo momento, após a absorção inicial dos poros dos grãos). A tensão superficial da água provoca a criação de "meniscos" entre as camadas de água adsorvida do entorno dos grãos, ocasionando assim o afastamento das partículas, o que explica o inchamento. $\mathrm{O}$ registro desse retardo no inchamento para os agregados de RCD, com a devida discussão, consiste em um "achado científico", dado o caráter inovador do resultado. Um achado científico implica na descoberta inédita de dados, materiais ou informações durante estudos científicos, resultando em novos e importantes conhecimentos, sem que exista uma

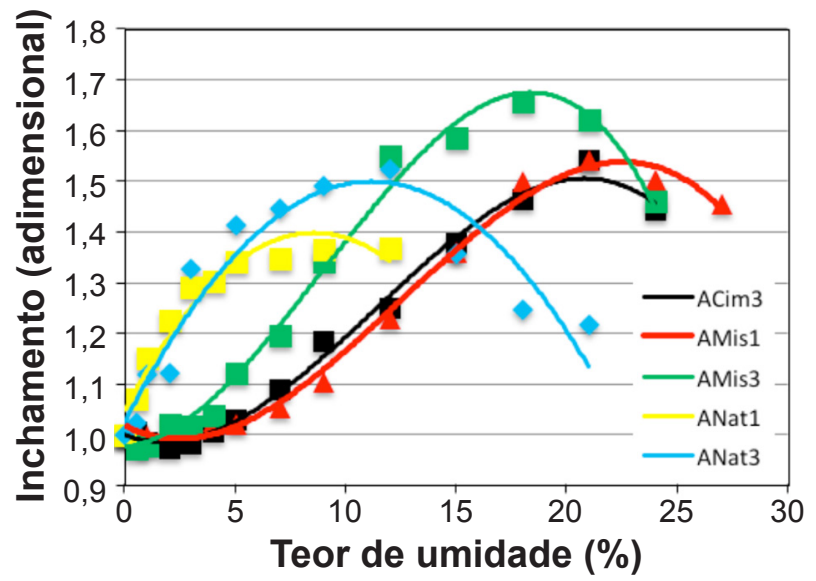

Figura 7: Curvas de inchamento dos agregados. [Figure 7: Aggregates bulking curves.]

finalidade específica em realizar-se esta descoberta.

Buscou-se, então, correlacionar o comportamento do inchamento com o TMP determinado para os agregados em estudo. Encontrou-se uma correlação moderada entre TMP e a umidade crítica (UC) obtida no ensaio de inchamento $\left(\mathrm{R}^{2} \cong 0,5\right.$ e $\left.\mathrm{R}=0,7\right)$, quando se utilizaram todos os dados. Retirando o ponto relativo ao agregado AMis1, que não se ajustou bem a esta regressão linear, obteve-se uma correlação muito forte, com coeficiente de determinação aproximadamente igual a um $\left(\mathrm{R}^{2} \cong 1,0\right)$, conforme pode ser visto na Fig. 8a. Isto mostrou que o teor de finos do agregado é capaz de explicar o comportamento da umidade
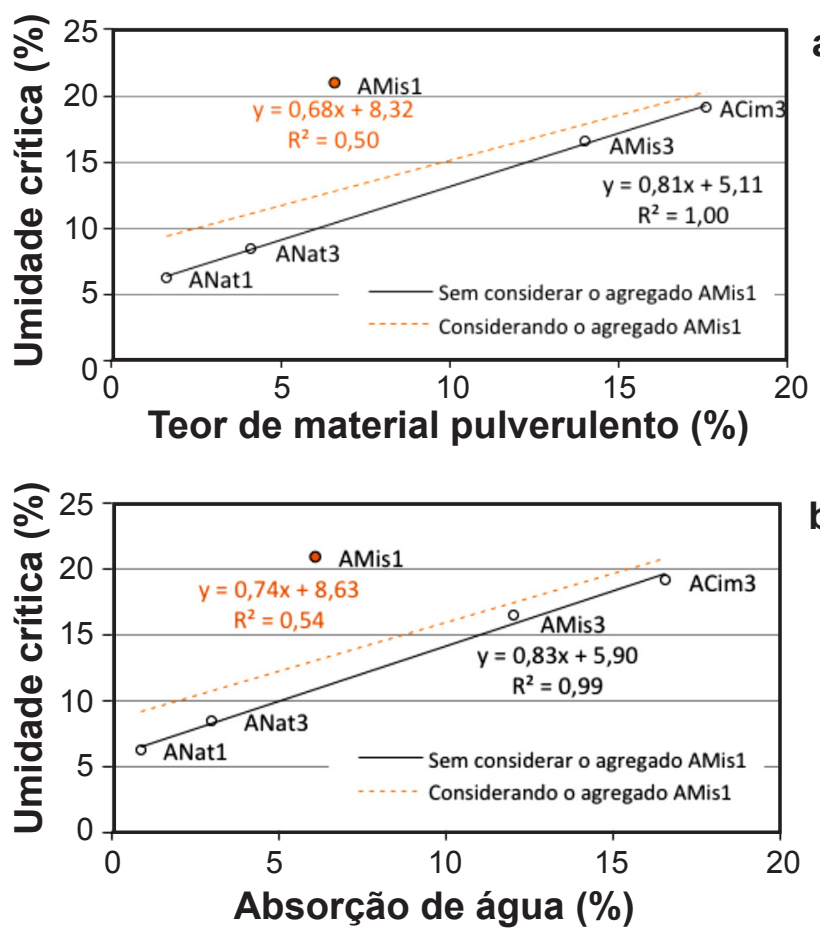

b)

Figura 8: Relação entre a umidade crítica e o teor de material pulverulento (a) e a absorção de água (b) dos agregados.

[Figure 8: Relationship between the critical moisture and the fine content ( $a$ ) and the water absorption (b) of aggregates.] 
crítica no ensaio de inchamento. Comportamento similar, conforme esperado em função da correlação já apresentada na Fig. 8a, foi obtido entre absorção de água dos agregados e a umidade crítica (Fig. 8b). Estes aspectos reforçam a necessidade de se caracterizar bem a absorção de água e o teor de material pulverulento dos agregados reciclados. Ademais, em função dos altos coeficientes de inchamento (CI) dos agregados de RCD (Tabela V), além das variações da UC, alerta-se para uma possível alta variabilidade da quantidade de materiais nos traços de argamassas, quando elas são dosadas em volume, situação adotada na prática das obras.

\section{Influência dos agregados nas argamassas}

$\mathrm{Na}$ Tabela VII apresenta-se a caracterização das argamassas no estado fresco, além de alguns parâmetros dos traços estudados. Apesar de se ter fixado visualmente a trabalhabilidade das argamassas, ocorreu uma pequena diferença nos resultados médios de índice de consistência. A maior diferença obtida, de $20 \%$, entre ACim3 e ANat3 é explicada pela mais elevada relação água/materiais secos da argamassa ACim3. A Fig. 9 apresenta a correlação obtida entre a massa unitária dos agregados e a relação água/materiais secos das argamassas. Observa-se uma correlação forte entre estas variáveis, em que cerca de $80 \%$ dos resultados referentes à quantidade de água necessária para dar a trabalhabilidade adequada às argamassas (representada no gráfico pela relação água/materiais secos) é explicada pela massa unitária dos agregados utilizados. Comportamento similar foi obtido em [36] com agregados naturais de rio e de rochas britadas, indicando que se existe um arranjo das partículas que gera maior densidade ou melhor empacotamento (caso dos agregados ANat1, ANat3 e AMis3), menor é a necessidade de água para garantir uma consistência similar nas argamassas. Assim, confirmam-se as observações de [37], em um estudo que avaliou a influência dos agregados de rochas britadas nas argamassas. Segundo esses autores, a distribuição granulométrica tem grande influência no comportamento reológico das argamassas, mas outros parâmetros como a morfologia, os teores das frações fina e graúda das areias e o empacotamento desses grãos também influenciam de modo significativo a trabalhabilidade das argamassas. Na Tabela VII também pode-se observar que a densidade de massa das argamassas foi menor com os agregados reciclados, quando comparados aos naturais; independentemente do tipo de agregado reciclado utilizado, houve uma redução na densidade das argamassas, quando comparadas ao agregado natural. Essa redução foi devido à maior porosidade do agregado reciclado (menor $\mathrm{ME}$ dos grãos), mas, principalmente, ao aumento na relação água/ materiais secos (visto que a densidade da água é inferior à dos sólidos que compõem as argamassas).

A retração foi medida por um período de 28 dias em, no mínimo, três corpos de prova para cada uma das argamassas estudadas. Os valores médios obtidos de retração ao longo do tempo estão compilados na Fig. 10. Observa-se que as argamassas produzidas com as areias naturais apresentaram menor retração total do que as elaboradas com agregados reciclados, conforme esperado. O comportamento de retração das argamassas foi semelhante, sendo dividido em quatro períodos bem característicos, conforme discutido a seguir. $\mathrm{O}$ primeiro intervalo de tempo, de $24 \mathrm{~h}$ a 5 dias, representa um período de pequenas variações dimensionais, inferiores a $0,20 \mathrm{~mm} / \mathrm{m}$. Neste intervalo, as curvas de retração se entrelaçam e não há diferenças significativas entre elas, o que permite inferir que não devem aparecer fissuras oriundas de retração nesse período, em revestimentos elaborados com essas argamassas. A argamassa com AMis1 representou uma exceção a esse comportamento, pois já apresentou uma retração da ordem de $1,4 \mathrm{~mm} / \mathrm{m}$, extremamente elevada, aos 5 dias. Este resultado pode ser justificado com base em dois argumentos principais: a) AMis1 é o agregado que possuiu maior volume de vazios, portanto, o pior arranjo de partículas; b) a argamassa produzida com ele foi a que possui a mais elevada relação água/materiais secos $(25,5 \%)$. A combinação desses dois fatores permite deduzir que havia maior quantidade de poros e de água livre na argamassa nas idades iniciais e, por isso, houve uma maior tensão capilar e uma maior retração plástica e por secagem inicial. O segundo intervalo, de 5 a 10 dias, foi caracterizado pela diferenciação entre as argamassas, definindo as que têm uma maior e uma menor retração; foi o período de variações dimensionais da ordem de 0,50 a $1,07 \mathrm{~mm} / \mathrm{m}$. Neste intervalo, a argamassa AMis1 estabilizou-se, o que pode significar que a maior parte da sua água livre já foi eliminada dos poros. Em contrapartida, a argamassa ACim3 sofreu a maior variação dimensional, intensificada a partir do $7^{\circ}$ dia; a variação

Tabela VII - Resultados médios da caracterização das argamassas no estado fresco e parâmetros dos traços. [Table VII - Average results of the characterization of fresh mortars and mix proportions parameters.]

\begin{tabular}{cccccc}
\hline $\begin{array}{c}\text { Tipo de } \\
\text { agregado }\end{array}$ & $\begin{array}{c}\text { Teor de finos totais } \\
\text { das argamassas }\end{array}$ & $\begin{array}{c}\text { Relação água/ } \\
\text { cimento }\end{array}$ & $\begin{array}{c}\text { Relação água/ } \\
\text { materiais secos }\end{array}$ & $\begin{array}{c}\text { Densidade de } \\
\text { massa }\left(\mathrm{g} / \mathrm{dm}^{3}\right)\end{array}$ & $\begin{array}{c}\text { Consistência } \\
(\mathrm{mm})\end{array}$ \\
\hline ANat1 & $26 \%$ & 1,8 & $22 \%$ & 2,01 & 267 \\
ANat3 & $28 \%$ & 1,6 & $20 \%$ & 1,97 & 229 \\
AMis1 & $20 \%$ & 1,8 & $25 \%$ & 1,83 & 258 \\
AMis3 & $27 \%$ & 1,6 & $22 \%$ & 1,95 & 258 \\
ACim3 & $29 \%$ & 1,6 & $25 \%$ & 1,79 & 275 \\
\hline
\end{tabular}




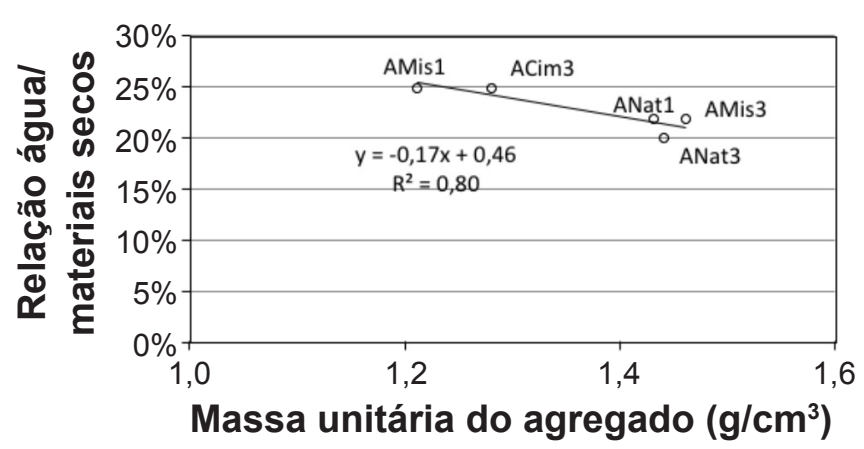

Figura 9: Correlação entre a relação água/materiais secos das argamassas e a massa unitária dos agregados.

[Figure 9: Correlation between the water/dry materials ratio of mortars and the apparent dry density of aggregates.]

brusca segue o mesmo padrão apresentado pela argamassa AMis1 no primeiro período avaliado. No terceiro intervalo, observa-se o início da estabilização das argamassas que ainda estavam retraindo, ANat1, ANat3 e AMis3, com variações entre 0,20 e $0,40 \mathrm{~mm} / \mathrm{m}$; em outra linha, a argamassa ACim3 retraiu bruscamente e chegou ao patamar da AMis1, com retração total da ordem de $1,63 \mathrm{~mm} / \mathrm{m}$. No quarto intervalo, a partir do $15^{\circ}$ dia de moldagem dos corpos de prova, não houve mais variações dimensionais significativas para quaisquer das argamassas; todas permaneceram invariáveis até os 28 dias, data da última medição de retração.

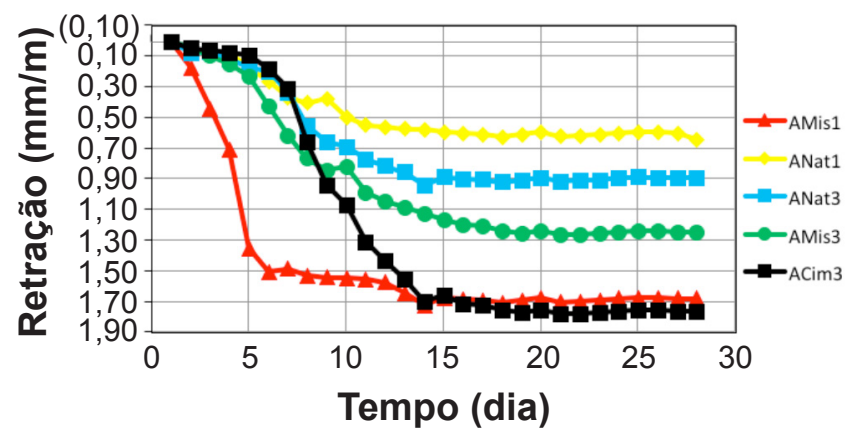

Figura 10: Retração média das argamassas ao longo do tempo.

[Figure 10: Average shrinkage of the mortars as a function of time]

Foram realizadas várias tentativas de correlação entre os valores de finos do agregado (TMP) e finos totais da argamassa com os resultados de retração obtidos aos 5 e 28 dias. As correlações que obtiveram a melhor qualidade de ajuste das regressões (maiores valores de $\mathrm{R}^{2}$ ) são mostradas na Fig. 11. Observou-se que existe uma correlação entre o TMP dos agregados e a retração máxima medida aos 28 dias, principalmente quando se descarta o resultado da argamassa elaborada com AMis1. O valor discrepante da argamassa elaborada com o agregado AMis1 tem um respaldo forte nos dados de caracterização do agregado. Esse agregado foi o que apresentou a menor massa unitária dentre todos, que, por sua vez, gerou o menor fator de empacotamento (Eo), assim como os mais altos valores de porosidade $(\eta)$ e índice de vazios (e). Isto veio a produzir a maior umidade crítica dentre todos os agregados. Com o pior arranjo entre as partículas, verificou-se uma alta demanda por água da argamassa. Todo esse conjunto de diferenças no agregado AMis1 provocou alterações nos valores de retração da argamassa, tornando discrepante o ponto da curva. No entanto, para a retração aos 5 dias não foi encontrada correlação significativa com o TMP dos agregados. Quem explicou melhor a retração inicial das argamassas, até os 5 dias de idade, foi o teor de finos total das argamassas, que inclui o fino proveniente dos aglomerantes (cimento e cal). Assim, pôde-se inferir que a retração até os 5 dias de idade das argamassas, ou seja, a retração plástica e a de secagem inicial irreversível, foi causada pelo teor de finos totais da argamassa (Fig. 12) e, consequentemente, pela quantidade de água livre nas argamassas. Já a retração total (final) foi fortemente influenciada pelo teor de finos dos agregados (TMP).

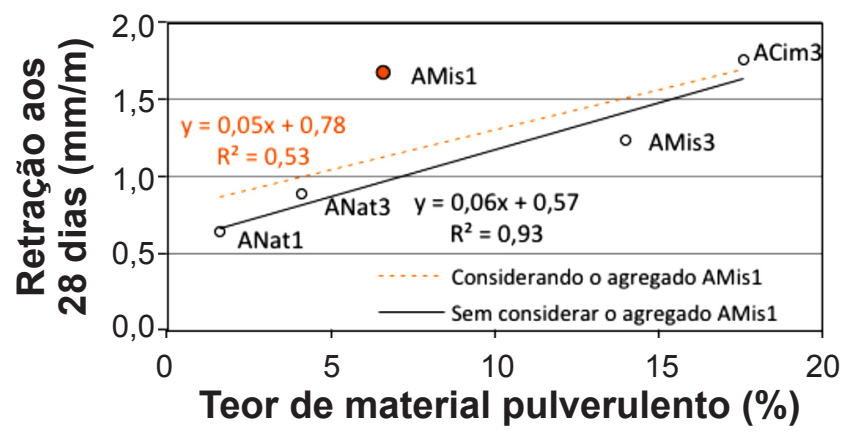

Figura 11: Relação entre a retração da argamassa aos 28 dias e o teor de material pulverulento do agregado.

[Figure 11: Relationship between the mortar shrinkage (28 days) and the fine content of aggregate.]

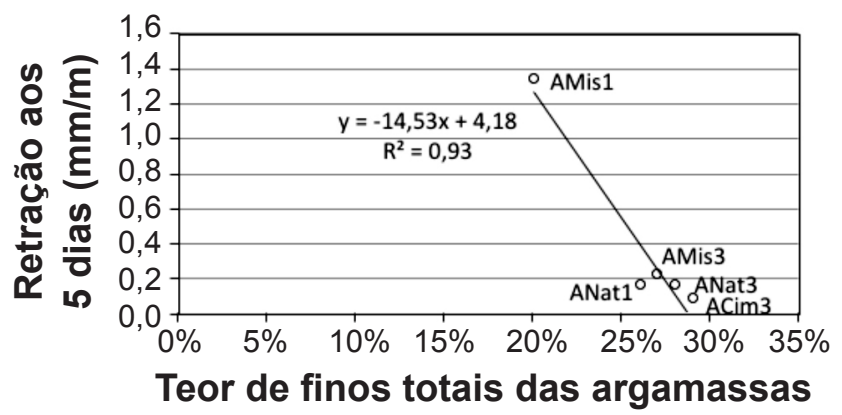

Figura 12: Relação entre a retração da argamassa aos 5 dias e o teor de finos totais das argamassas.

[Figure 12: Relationship between the mortar shrinkage (5 days) and the total fine content of mortars.]

A Fig. 13 apresenta os resultados obtidos nos ensaios de determinação das resistências mecânicas das argamassas, avaliados aos 28 dias após a moldagem. Comparando-se os resultados obtidos entre as argamassas com agregados de mesma natureza e granulometrias diferentes (ANat3 com ANat1 e AMis3 com AMis1), observou-se que os agregados mais grossos, de maior dimensão máxima característica (DMC), apresentaram as maiores resistências à tração e à compressão. Isto porque as argamassas com os agregados mais grossos demandaram menos água (menor relação água/ 
materiais secos), o que significou uma menor porosidade da pasta. A relação entre as resistências e a relação água/ materiais secos é mostrada na Fig. 14a. As argamassas elaboradas com os agregados reciclados apresentaram resistências um pouco inferiores às argamassas com a areia natural de mesma DMC. Neste caso, isto pode ser explicado pela presença da cal nas argamassas de areia natural, o que aumentou o teor total de aglomerantes delas. Observa-se também na Fig. 13 que as resistências da argamassa com ACim3 resultaram inferiores às da argamassa com AMis3, o que pode ser explicado tanto pela alta porosidade do agregado cimentício (Fig. 4), refletida na sua massa específica, como pela alta demanda de água produzida na argamassa (água/ materiais secos igual a 25\%). Esta alta demanda de água foi explicada pelo elevado teor de finos do ACim3 (maior TMP), além da fração de menor dimensão ser mais fina, conforme foi verificado no ensaio de granulometria a laser (Fig. 3).
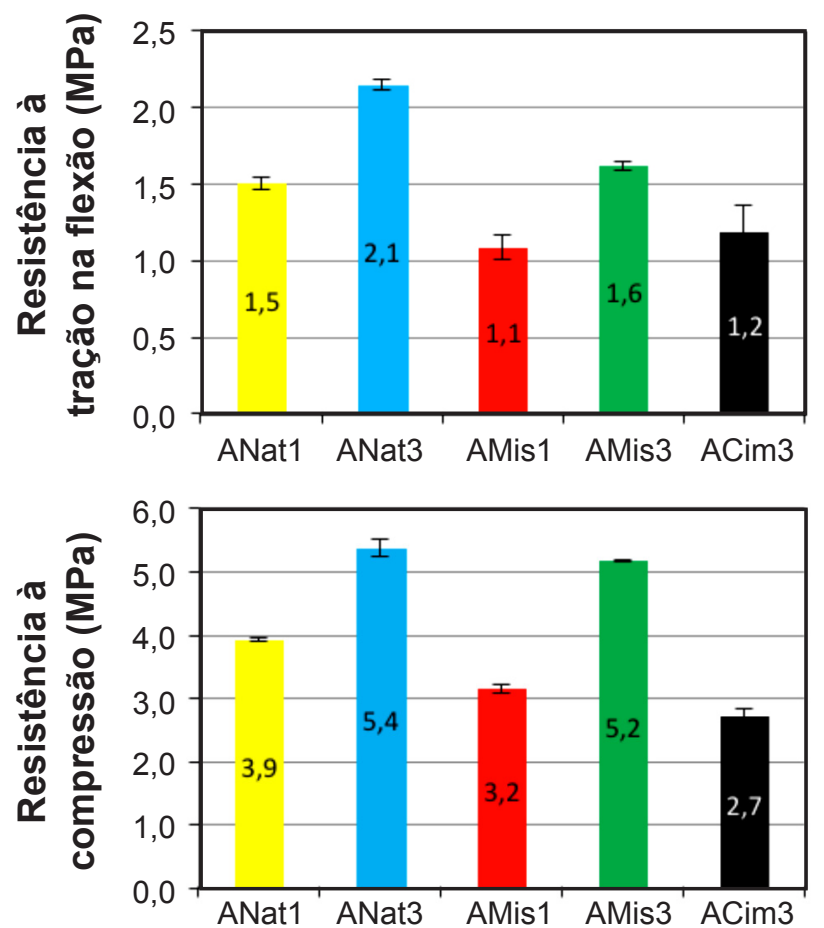

Figura 13: Resistência à tração na flexão (a) e resistência à compressão (b) das argamassas aos 28 dias (valores médios e desvios-padrões).

[Figure 13: Flexural strength (a) and compressive strength of mortars - 28 days (mean values and standard deviations).]

Na Fig. 14b, tentou-se uma correlação entre a massa unitária das areias e as resistências das argamassas. Salientase que foram testadas também correlações das resistências das argamassas com o índice de vazios das areias, mas os valores de coeficiente de determinação encontrados foram baixos, demostrando haver uma fraca correlação entre essas variáveis. Neste caso, as correlações obtidas foram moderadas a fortes $(R>0,8)$. O coeficiente de determinação $\left(\mathrm{R}^{2}\right)$ deve ser interpretado como a proporção de variação total de uma variável Y (resistência das argamassas), sendo
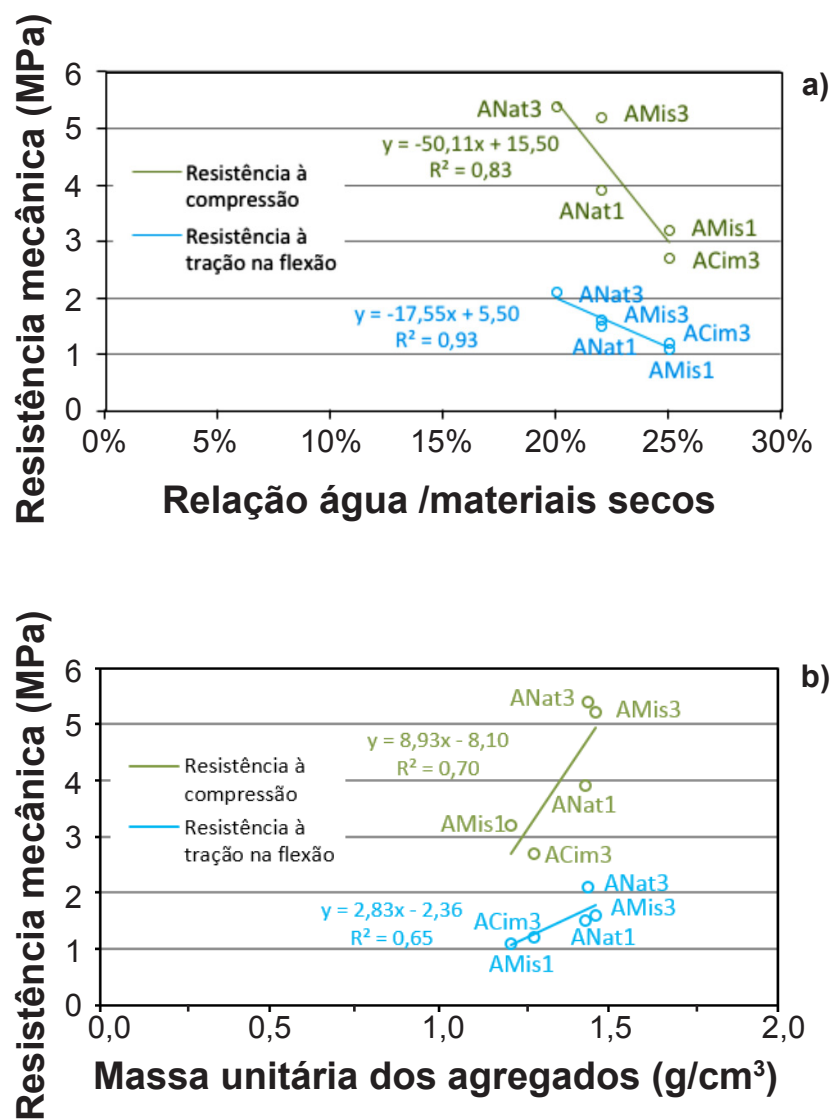

Figura 14: Resistência mecânica das argamassas em função da: (a) relação água/materiais secos; e (b) massa unitária dos agregados. [Figure 14: Mortars mechanical strength as a function of: (a) water] dry material ratio; and (b) apparent dry density of aggregates.]

explicada pela variação da variável X (massa unitária). Assim, a massa unitária dos agregados explica 65\% e $70 \%$ das resistências à tração e à compressão, respectivamente. Acredita-se que as correlações não foram ainda melhores porque as argamassas têm, em função das premissas de dosagem, composições e proporcionamentos um pouco diferentes, parâmetros estes que também influenciam nas resistências mecânicas. Isto pode indicar que a massa unitária é um parâmetro interessante para qualificar os agregados em geral para argamassas, inclusive os reciclados de RCD, conforme proposto em [38, 39] para os agregados naturais e, recentemente, em [36] para as areias de britagem de rochas.

\section{CONCLUSÕES}

A caracterização dos agregados pelos distintos métodos (quanto à distribuição granulométrica por peneiramento e granulometria a laser, análise por imagem, cálculo dos parâmetros de interação entre as partículas, determinação do coeficiente de inchamento e seu teor de umidade crítica e determinação das massas específicas e unitárias) foi fundamental para o entendimento do comportamento dos materiais estudados neste trabalho, permitindo, assim, chegarse às seguintes conclusões: i) o mesmo processo de moagem gerou distribuições granulométricas muito semelhantes para 
os agregados reciclados de composição mista e cimentícia, apesar da diferença de composição e origem do resíduo; ii) nos agregados de resíduos de construção e demolição (RCD), o teor de material pulverulento resultou muito superior, cerca de 3 a 4 vezes, ao valor obtido para a areia natural; além disso, a fração inferior a $0,075 \mathrm{~mm}$ dos agregados reciclados foi também mais fina do que a da areia natural; iii) verificouse uma correlação linear crescente $\left(R^{2} \cong 1\right)$ entre a absorção de água e o teor de materiais pulverulentos dos agregados; iv) tendo em vista os altos coeficientes de inchamento, além das variações da umidade crítica dos agregados de RCD, alerta-se para uma possível alta variabilidade da quantidade de materiais nos traços das argamassas, quando elas são dosadas em volume nas obras; v) os agregados provenientes de RCD não podem ser classificados apenas quanto à composição do material (cerâmico ou cimentício), devendo ser feita uma avaliação completa das suas características, as quais podem ser muito variáveis de acordo com a origem do resíduo e seu processamento; vi) percebeu-se um comportamento diferenciado nas curvas de inchamento dos agregados reciclados em comparação com as curvas convencionalmente obtidas para areia natural; para os agregados de RCD elas apresentaram um retardo no princípio do inchamento, havendo inicialmente uma manutenção do volume e até mesmo uma pequena retração do material; vii) os agregados mais grossos, de maior dimensão máxima característica, propiciam maiores resistências à tração e à compressão das argamassas; viii) existe uma boa correlação entre massa unitária dos agregados (parâmetro que conjuga, por meio do encaixe espontâneo do material, a granulometria, a forma e a massa específica dos grãos) e a quantidade de água das argamassas, necessária para produzir trabalhabilidade adequada às misturas (medida, na presente pesquisa, pela relação água/ materiais secos); ix) a retração das argamassas com RCD pôde ser parcialmente explicada pelos seguintes parâmetros: teor de material pulverulento do agregado (retração aos 28 dias) e teor de finos totais das argamassas (retração aos 5 dias); x) as resistências das argamassas (à compressão e à tração na flexão) e a massa unitária dos agregados podem ser correlacionadas por regressão linear crescente $(R>0,8)$. Essas correlações não foram ainda melhores porque as argamassas têm, em função das premissas de dosagem, composições e proporcionamentos um pouco diferentes, parâmetros estes que também influenciam na resistência.

\section{AGRADECIMENTOS}

Os autores agradecem à Coordenação de Aperfeiçoamento de Pessoal de Nível Superior (CAPES) pela bolsa de mestrado e ao Conselho Nacional de Desenvolvimento Científico e Tecnológico $(\mathrm{CNPq})$, pelas bolsas de pesquisador (PQ). Também agradecem ao acadêmico Paulo César Martins Filho (bolsista do Programa Jovens Talentos para Ciência), pela contribuição no trabalho experimental. Agradecimentos especiais são expressos às empresas colaboradoras da pesquisa: Carlos Campos Consultoria e Construções Ltda., pela colaboração na caracterização dos agregados; ICAL Indústria de Calcinação Ltda., pela doação da cal; RNV Gestão e Soluções em Resíduos, pelo fornecimento do agregado reciclado utilizado; e Construtora Rodrigues da Cunha, pelo apoio e doação dos demais materiais necessários à realização do trabalho.

\section{REFERÊNCIAS}

[1] A.S.G. Mesquita, Holos 2 (2012) 58.

[2] ABRELPE, "Panorama dos resíduos sólidos no Brasil 2013", <http://www.abrelpe.org.br/Panorama/ panorama2012.pdf>, ac. 17/12/2016.

[3] S.C. Angulo, A. Mueller, Mater. Struct. 42 (2009) 739.

[4] C. Ulsen, H. Kahn, G. Hawlitschek, E.A. Masini, S.C. Angulo, Waste Manage. 33 (2013) 656.

[5] P.H. Gonçalves, M.C.G. Brandstetter, Conex. Acad. 3 (2013) 11.

[6] Min. Meio Amb., Cons. Nac. Meio Amb. - CONAMA, Resol. no 307 (2002).

[7] S.M. Levy, P.R.L. Helene, Anais I Simp. Brasil. Tecn. Argamas., Goiânia, GO (1995) 315.

[8] L.F.R. Miranda, S.M.S. Selmo, Anais $4^{\circ}$ Simp. Brasil. Tecn. Argamas., Brasília, DF (2001) 225.

[9] S.C. Angulo, C. Ulsen, P.M. Carrijo, R.M. Silva, V.M. John, Proc. Int. RILEM Conf. Use Recycl. Mater. Build. Struct. 40 (2004) 87.

[10] L.F.R. Miranda, S.M.S. Selmo, Anais Int. RILEM Conf. Use Recycl. Mater. Build. Struct., Barcelona (2004).

[11] L.F.R. Miranda, S.M.S. Selmo, Constr. Build. Mater. 20 (2006) 615.

[12] L.T. Assunção, G.F. Carvalho, M.S. Barata, Exacta 5, 2 (2007) 223.

[13] V. Corinaldesi, Cem. Concr. Compos. 31 (2009) 505.

[14] V. Corinaldesi, G. Mariconi, Constr. Build. Mater. 23 (2009) 289.

[15] R.R. Menezes, J. Farias Filho, H.S. Ferreira, G.A. Neves, H.C. Ferreira, Cerâmica 55 (2009) 263.

[16] E.C.R. Silva, A.J. Bezerra, C.F.C. Silva, L.F.R. Miranda, Anais IX Simp. Bras. Tecn. Argamas., Belo Horizonte, MG (2011).

[17] C. Neno, J. Brito, R. Veiga, Mater. Res. 17 (2014) 168.

[18] J. Silva, J. de Brito, R. Veiga, J. Mater. Civil Eng. 22 (2010) 236.

[19] L.F.R. Miranda, C.S. Constantino, C.R. Monich, A.A. de M. Neto, J. Mater. Civil Eng. 25, 2 (2012) 236.

[20] I. Martínez, M. Etxeberria, E. Pavon, N. Días, Constr. Build. Mater. 49 (2013) 384.

[21] J.R. Jiménez, J. Ayuso, M. López, J.M. Fernadéz, J. de Brito, Constr. Build. Mater. 40 (2013) 679.

[22] J.O. Malta, V.S. Silva, J.P. Gonçalves, Rev. Eletr. Gest. Tecnol. Ambient. 1, 2 (2013) 176.

[23] L.H Antes, A.L. Pires, S. Rudek, R.G. Scherer, R.G. Felipeto, R.P. Oliveira, A.L.G. Gastaldini, Anais XXVI Congr. Reg. Inic. Cient. Tecn. Eng., Alegrete, RS (2014).

[24] E.F. Ledesma, J.R. Jiménez, J.M. Fernandéz, A.P. Galvin, F. Agrela, A. Barbudo, Constr. Build. Mater. 71 
(2014) 289.

[25] L.L Brasileiro, J.M.E. Matos, Cerâmica 61 (2015) 178. [26] J.C. Ferreira, T.M. Grabois, G.C.S. Calcado, R.D. Toledo Filho, Key Eng. Mater. 634 (2014) 300.

[27] A.C.C. Girardi, L. Moreira, P.C. Martins Filho, H. Carasek, Anais $58^{\circ}$ Congr. Bras. Concr., Belo Horizonte (2016) 1.

[28] I. Ribeiro, R.R. Angelim, R.C. Guimarães, Anais IV Geojovem - Congr. Bras. Mec. Solos Eng. Geotécn., Goiânia, GO (2014).

[29] H.P. Caputo, Mecânica dos solos e suas aplicações, Vol. 1, $4^{\text {a }}$ Ed., LTC, Rio de Janeiro (2011).

[30] M. Westerholm, B. Lagerblad, J. Silfwerbrand, E. Forssberg, Cem. Concr. Compos. 30 (2008) 274.

[31] L.F.R. Miranda, S.M.S. Selmo, Anais III Simp. Bras. Tecn. Argamas., Vitória, ES (1999) 295.

[32] A.M. Buttler, E.F. Machado Júnior, VI Sem. Desenv.
Sust. Rec. Constr. Civil - Mater. Rec. Aplic., S. Paulo (2003). [33] O. Cascudo, in Materiais de construção civil e princípios de ciência e engenharia de materiais, Vol. 1, IBRACON, S. Paulo (2017) 143.

[34] S.M. Levy, P.R.L. Helene, Bol. Técn. Esc. Polit. USP BT/PCC/318 (2002).

[35] A.O. Gomes, E.P. Presa, VIII Enc. Nac. Tecn. Amb. Constr., Salvador (2000) 1092.

[36] H. Carasek, R.C. Araújo, R. Angelim, O. Cascudo, Rev. Matéria 21, 3 (2016) 714.

[37] C. de Freitas, M.R.M.M. da Costa, Anais XIII Enc. Nac. Tecn. Amb. Constr., Canela, RS (2010).

[38] A.M.P. Carneiro, M.A. Cincotto, V.M. John, Amb. Constr. 1, 2 (1997) 37.

[39] G. de Shutter, A.M. Poppe, Constr. Build. Mater. 18 (2004) 517.

(Rec. 17/03/2017, Rev. 20/07/2017, 27/08/2017, Ac. 28/11/2017) 